Research Article

\title{
Flexural Behavior of Posttensioned Concrete Beams with Unbonded High-Strength Strands
}

\author{
Min Sook Kim (iD) and Young Hak Lee (i) \\ Department of Architectural Engineering, Kyung Hee University, 1732 Deogyeong-daero, Yongin 17104, Republic of Korea \\ Correspondence should be addressed to Young Hak Lee; leeyh@khu.ac.kr
}

Received 21 November 2019; Accepted 17 March 2020; Published 9 April 2020

Academic Editor: Luís Evangelista

Copyright ( 92020 Min Sook Kim and Young Hak Lee. This is an open access article distributed under the Creative Commons Attribution License, which permits unrestricted use, distribution, and reproduction in any medium, provided the original work is properly cited.

\begin{abstract}
This paper assesses the applicability of high-strength strands to current design codes and various existing equations. To evaluate the flexural performance of posttensioned concrete members with Grade 2400 strands, a flexural experiment was conducted on eleven specimens. Test variables included the tensile strength of strands, the number of strands, the cross-section shape, and anchorage zone reinforcement details. The test results were compared with ACI 318-19, AASHTO, and equations of Du and Tao, Naaman and Alkhari, and Harajli to evaluate the applicability of flexural strength equations for posttensioned concrete members using unbonded high-strength strands. Results indicated that the provisions of ACI 318-19 and AASHTO design codes and the existing equations underestimated the increased stress of the high-strength strands. Additionally, results demonstrate that improved equations are needed to consider the strain-compatibility model, plastic hinge length, and relationship between bonded reinforcement, concrete, and prestressing steel in posttensioned members using high-strength strands.
\end{abstract}

\section{Introduction}

High-strength strands (e.g., Grade 2070 strands, Grade 2160 strands, and Grade 2400 strands) have been developed, which are higher in strength than conventional Grade 1860 strands. High-strength tendons have high yield and tensile strength. These may contribute to reducing the section size and increasing the span.

However, current design methods intended for normalstrength tendons are not always directly applicable to highstrength tendons because of differences in the material properties. While many researchers have dealt with flexural behavior of posttensioned concrete beams with normalstrength tendons, very little information is available on the behavior of high-strength tendons. Park et al. [1] investigated the effect of high-strength strands on the flexural behavior of long-span, posttensioned girders using the compressive strength of concrete and tensile strength of strands as variables. They reported that the ACI 318 code estimated the flexural strength well and found a similar tendency of crack patterns, crack spacing, and crack width, regardless of the tensile strength of the strands. However, they confirmed that the maximum crack width in the specimen with high-strength strands and stress values in the high-strength strands and deformed rebar under the full service load exceeded the permissible values of the ACI 318 code. Park et al. [2] analyzed the applicability of high-strength strands to provisions of the current design codes such as ACI 318 and CSA A23.3 based on the strain-compatibility analysis considering the tensile strength of the prestressing strand, the yield-to-tensile strength ratio, and the number of prestressing strands as variables. The test results showed that the current codes predicted unconservative results for the preyield region of high-strength strands and flanged section, and a modified flexural strength equation was proposed to consider the influences of flanged sections and high-strength strands. Although numerous test results have confirmed that current codes have difficulty predicting flexural performance in posttensioned members using high-strength strands, the provisions of both ACI 318 [3] and AASHTO [4] codes were suggested based on the structural performance of the posttensioned members using Grade 1860 strands. In addition, the current codes proposed the design process for 
fully prestressed concrete members, but they do not include guidelines for partially prestressed concrete members [5]. There have been several studies $[1,2]$ focused on the applicability of current design codes to bonded high-strength strands, which are used commonly in large-scale structure, whereas investigations of unbonded high-strength strands, which have different flexural behavior than bonded strands, are limited.

In this study, flexural tests on eleven posttensioned concrete members were performed in order to evaluate the flexural behavior of unbonded high-strength single-strand tendons according to the tensile strength of strands, the number of strands, the cross-section shape, and details of the anchorage zone reinforcement. The test results were also compared to examine the validity of existing methods for determination of stress of high-strength tendons including ACI 318-19, AASHTO, and equations of Du and Tao, Naaman and Alkhari, and Harajli [3, 4, 6-8].

\section{Equations to Calculate Unbonded Strand Stress}

In posttensioned concrete members, the stress in the unbonded strand $\left(f_{p s}\right)$ is used to predict the nominal moment capacity and is calculated by adding the increase of the ultimate stress in the strand $\left(\Delta f_{p s}\right)$ to the effective prestressing stress $\left(f_{p e}\right)$. Although the stress in the bonded strand can be calculated based on strain compatibility, the stress in the unbonded strand is difficult to predict because the strain increase in the unbonded strand is much less than that in the bonded strand, as shown in Figure 1. Hence, many researchers have proposed methods to determine $\Delta f_{p s}$ accurately.

The ACI building code [3] adopted equation (1) to calculate the stress in prestressing steel based on the experimental results of Mattock et al. [9] in 1971. In equation (1), the increase in the ultimate strand stress $\Delta f_{p s}$ is expressed by the ratio of compressive strength of concrete $\left(f_{c}^{\prime}\right)$ to the prestressing steel ratio $\left(\rho_{p}\right)$. Mojtahedi and Gamble [10] suggested that the span-depth ratio is an important variable for predicting the ultimate stress in unbonded strands based on the finding that as the spandepth ratio increased, the strain of the tie on the central hinge decreased drastically by an analytical model of a conceptual triangular truss. Since 1983, the ACI building code has calculated the ultimate stress in an unbonded strand using equation (1) when the span-depth ratio is under 35 and equation (2) when the span-depth ratio $(l / d)$ is over 35 based on research conducted by Mojtahedi and Gamble [10]:

$$
\begin{gathered}
f_{p s}=f_{p e}+70+\frac{f_{c}^{\prime}}{100 \rho_{p}}<f_{p y} \\
\operatorname{or}\left(f_{p e}+420\right)[\mathrm{MPa}], \\
f_{p s}=f_{p e}+70+\frac{f_{c}^{\prime}}{300 \rho_{p}}<f_{p y} \\
\operatorname{or}\left(f_{p e}+210\right)[\mathrm{MPa}] \text { for }\left(\frac{l}{d}\right)>35 .
\end{gathered}
$$

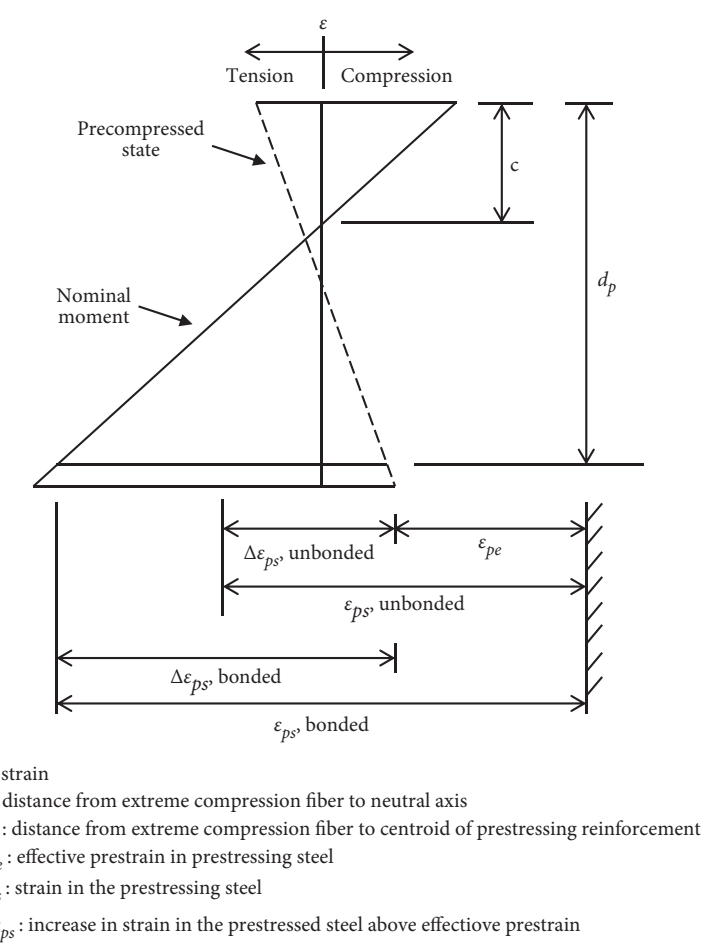

FIgURE 1: Strain distribution comparison at section of the maximum moment.

Du and Tao [6] pointed out that there is no consideration of bonded reinforcement in the ACI building code and carried out a flexural experiment on 26 concrete beam specimens with rectangular cross section under two-point loading, based on the compressive strength of concrete, the cross-sectional area of prestressed steel $\left(A_{p s}\right)$, and the crosssectional areas of non-prestressed tension steel. The spandepth ratio was kept constant at 19.1. Results of the experiment indicated that the stress in the unbonded prestressed strand at ultimate decreased as the amount of bonded reinforcement increased. Based on this experimental observation, Du and Tao proposed equations (3) and (4) to predict the stress in unbonded strands at ultimate considering the combined reinforcement index (CRI), which can be derived by the sum of the reinforcement index of the strand $\left(q_{e}\right)$ and the reinforcement index of bonded reinforcement $\left(q_{s}\right)$. In equation (4), $\rho_{p}$ is the ratio of prestressed steel and $\rho_{s}$ is the ratio of bonded steel:

$$
\begin{aligned}
f_{p s} & =f_{p e}+\left(786-1920 q_{0}\right)(\mathrm{MPa}), \\
q_{0} & =q_{p e}+q_{s}, \\
q_{p e} & =\rho_{p} \frac{f_{p e}}{f_{c}^{\prime}} \\
q_{s} & =\rho_{s} \frac{f_{y}^{\prime}}{f_{c}^{\prime}}
\end{aligned}
$$

Naaman and Alkhari [7] suggested equations (5) to (7) for predicting the stress in unbonded tendons as a 
modification of the ACI building code, which did not consider loading patterns. They introduced the bond reduction coefficient $\Omega_{u}$ to consider that the increase of stress in unbonded tendons is substantially smaller than that for bonded tendons. The bond reduction coefficient depends on the loading patterns and tendon profile:

$$
\begin{aligned}
f_{p s} & =f_{p e}+\Omega_{u} E_{p s} \varepsilon_{c u}\left(\frac{d_{p}}{c}-1\right) \frac{L_{1}}{L_{2}} \\
\Omega_{u} & =\frac{2.6}{L / d_{p}}(1-\text { point loading }) \\
\Omega_{u} & =\frac{5.4}{L / d_{p}}(2-\text { point or uniform loading })
\end{aligned}
$$

where $\Omega_{u}$ is the bond reduction coefficient at ultimate nominal resistance, $E_{p s}$ is the modulus of elasticity of prestressing steel, $\varepsilon_{c u}$ is the ultimate concrete compression strain, $L$ is the span length, $L_{1}$ is the length of the loaded span or the sum of the lengths of loaded spans, affected by the same tendon, and $L_{2}$ is the length of tendon between end anchorages.

The AASHTO-LRFD code [4] adopted Naaman and Alkhairi's equation in AASHTO 1994, but it was replaced in AASHTO 1998 with equations (8) to (10). Roberts-Wollmann et al. [11] verified the accuracy of the AASHTO-LRFD code based on work performed by MacGregor [12]. They confirmed that the new equation used in the AASHTO code gave more reasonable predictions of the stress in unbonded strands compared with the ACI building code:

$$
\begin{aligned}
f_{p s} & =f_{p e}+6300\left(1-\frac{d_{p}-c}{l_{e}}\right) \leq f_{p y}(\mathrm{MPa}), \\
l_{e} & =\frac{2 l_{i}}{2+N_{s}}, \\
c & =c_{y}=\frac{A_{p s} f_{p s}+A_{s} f_{y}-A_{s}^{\prime} f_{y}^{\prime}-0.85 \beta_{1} f_{c}^{\prime}\left(b-b_{w}\right) h_{f}}{0.85 \beta_{1} f_{c}^{\prime} b_{w}},
\end{aligned}
$$

where $l_{e}$ is the effective tendon length, $l_{i}$ is the length of tendon between anchorages, $N_{s}$ is the number of support hinges required to form a mechanism crossed by the tendon, $f_{y}^{\prime}$ is the yield strength of compressive reinforcement, $A_{s}$ is the area of nonprestressed longitudinal tension reinforcements, $\beta_{1}$ is the concrete strength factor, $b$ is the width of the compression face of a member, $b_{w}$ is the web width, and $h_{f}$ is the flange depth.

Harajli [8] conducted a comprehensive study but still encountered significant scatter in predicting test data, stating that the AASHTO code was more rational than the ACI code. Harajli [8] derived an equation based on the concept of a collapse mechanism for developing a general strain-compatibility model, as shown in equations (11) to (14). In addition, Harajli [8] provided the simplified equation given in equation (11) without significant loss of accuracy, as shown in equation (13):

$$
\begin{aligned}
f_{p s} & =f_{p e}+\frac{N_{p} E_{p s} \varepsilon_{c u}}{L_{a} / d_{p}}\left(1-\frac{c}{d_{p}}\right) \leq 0.95 f_{p y}, \\
N_{p} & =\left(\frac{20.7}{f}+10.5\right) n_{p}^{+}+10.5 n_{p}^{-}, \\
f_{p s} & =f_{p e}+\frac{420 N_{p}}{L_{a} / d_{p}}\left(1-\frac{c_{e}}{d_{p}}\right) \leq 0.95 f_{p y}, \\
c_{e} & =\frac{A_{p s} f_{p e}+A_{s} f_{y}}{0.85 \beta_{1} f_{c}^{\prime} b}
\end{aligned}
$$

where $N_{p}$ is a combined continuity and load parameter, $L_{a}$ is the length of the tendon between anchorages, $n_{p}^{+}$and $n_{p}^{-}$are the numbers of positive and negative plastic hinges, respectively, $f$ is the loading pattern coefficient, and $f_{p y}$ is the yield strength of the prestressing steel.

Table 1 presents a comparison of the parameters considered in the provisions of ACI [3] and AASHTO [4] and the proposed equations (6)-(8) for the prediction of stress in unbonded strands.

\section{Experimental Program}

3.1. Specimen Details. In this study, to analyze the flexural behavior of unbonded high-strength strands, eleven oneway slab specimens were fabricated considering the tensile strength of the prestressing strands, the number of strands, the shape of the cross section, and the reinforcement details of the anchorage zone as variables. Tendon tensile strengths of $1860 \mathrm{MPa}$ and $2400 \mathrm{MPa}$ were used, and the strands were arranged from 1 to 4 . Specimens were fabricated with a rectangular cross section or I-shaped cross section in order to observe the influence of the cross-section shape. In posttensioned concrete members, the prestressing forces were applied as compressive forces onto the concrete via anchorage devices. If failure occurs in the anchorage zone before flexural failure, it is considered brittle failure; the anchorage zone should be designed not to fail before flexural failure occurs. The distribution of tensile force according to the anchoring method of the strands and the stress applied to the concrete should be considered. In addition, in the case of bonded strand and concrete, it is normal to not have any effects of flexural moment on the anchorage zone, but in the case of unbonded strands, when the flexural moment is applied, the compressive force applied to the anchorage zone increases and failure can occur. The reinforcement details of the anchorage zone were considered as variables to analyze the influence of the flexural moment on the anchorage zone. U-shaped hairpin and closed stirrup details according to ACI 318-19 code were considered as variables. The specimens were $750 \mathrm{~mm}$ wide, $350 \mathrm{~mm}$ high, and $4000 \mathrm{~mm}$ long, and the span-depth ratio was 11.4. The compressive strength of concrete used for the fabrication of the specimens was $35 \mathrm{MPa}$. The average size of the coarse aggregate was $25 \mathrm{~mm}$ that does not exceed three-fourth the minimum clear spacing between reinforcing bars and prestressed reinforcements. Since the clear spacing of posttensioning ducts 
TABLE 1: Comparison of the parameters considered in the proposed equations and the provisions in ACI and AASHTO.

\begin{tabular}{|c|c|c|c|c|c|}
\hline \multirow[b]{2}{*}{ Authors/Code } & \multirow{2}{*}{$\begin{array}{l}\text { Parameters used in the equations for stress in } \\
\text { unbonded strands }\end{array}$} & \multicolumn{3}{|c|}{ Factors included in the equations } & \multirow{2}{*}{$\begin{array}{l}\text { Consideration for } \\
\text { high-strength } \\
\text { strands }\end{array}$} \\
\hline & & $\begin{array}{l}\text { Bonded } \\
\text { reinforcement }\end{array}$ & $\begin{array}{l}\text { Plastic hinge } \\
\text { length }\end{array}$ & $\begin{array}{l}\text { Loading } \\
\text { pattern }\end{array}$ & \\
\hline ACI & $f_{p e}, A_{p s}, f_{p y}, f_{c}^{\prime}, L / d_{p}$ & $\mathrm{X}$ & $\mathrm{X}$ & $\mathrm{X}$ & $\mathrm{X}$ \\
\hline $\mathrm{Du}$ and Tao & $f_{p e}, A_{p s}, A_{s}, f_{y}, f_{c}^{\prime}$ & $\mathrm{O}$ & $\mathrm{X}$ & $\mathrm{X}$ & $\mathrm{X}$ \\
\hline $\begin{array}{l}\text { Naaman and } \\
\text { Alkhari }\end{array}$ & $f_{p e}, A_{p s}, A_{s}, f_{y}, f_{c}^{\prime}, L / d_{p}, \Omega_{u}, L_{1}, L_{2}$ & $\mathrm{O}$ & $\mathrm{O}$ & $\mathrm{O}$ & $\mathrm{X}$ \\
\hline AASHTO & $f_{p e}, A_{p s}, A_{s}, f_{p y}, f_{y}, f_{c}^{\prime}, L / d_{p}, N_{s}$ & $\mathrm{O}$ & $\mathrm{O}$ & $\mathrm{X}$ & $\mathrm{X}$ \\
\hline Harajli & $f_{p e}, A_{p s}, A_{s}, f_{p y}, f_{y}, f_{c}^{\prime}, L / d_{p}, N_{p}$ & $\mathrm{O}$ & $\mathrm{O}$ & $\mathrm{O}$ & $\mathrm{X}$ \\
\hline
\end{tabular}

shall be designed more than $4 / 3$ of coarse aggregate size, the minimum clear spacing of anchorage was designed $94 \mathrm{~mm}$. The cross section of the specimens was determined to consider the spacing of reinforcements and ducts. Minimum bonded reinforcement in posttensioned members with unbonded tendons was required by the ACI 318-19 code to ensure flexural behavior. To meet the minimum amount of bonded deformed longitudinal reinforcement, four tensile rebars with yield strength of $400 \mathrm{MPa}$ and a $13 \mathrm{~mm}$ diameter and two compressive rebars were placed. Minimum shear reinforcement is required to satisfy the condition that $V_{u}$ is greater than $0.5 \varnothing V_{c}$. Therefore, stirrups with a diameter of $10 \mathrm{~mm}$ were placed with $200 \mathrm{~mm}$ spacing according to the minimum shear reinforcement area and the maximum spacing of shear reinforcement requirements of ACI 318-19. The anchorage zone was designed in accordance with ACI 318-19 as well. For each group of six or more anchorage devices, $n+1$ hairpin bars or closed stirrups using rebars with a diameter of $10 \mathrm{~mm}$ were installed, where $n$ is the number of anchorage devices. The hairpin bars or closed stirrups shall be placed with the legs extending into the slab perpendicular to the edge. The center portion of the hairpin bars or closed stirrups shall be placed perpendicular to the plane of the slab from $3 \mathrm{~h} / 8$ to $\mathrm{h} / 2$ ahead of the anchorage devices. U-shaped hairpin bars and closed stirrups for test specimens were made of rebars with a diameter of $13 \mathrm{~mm}$ and $10 \mathrm{~mm}$, respectively. The tendon profile was parabolic, with $120 \mathrm{~mm}$ eccentricities and tendons anchored at both ends by circular anchorages, with an yield strength of $490 \mathrm{MPa}$. The strands which were used in specimens were seven-wire prestressing strands with $15.2 \mathrm{~mm}$ diameter and $138.7 \mathrm{~mm}^{2}$ cross-sectional area. The yield strength of Grade 2400 and 1860 strands was $2160 \mathrm{MPa}$ and $1674 \mathrm{MPa}$, respectively. The notation used for specimens is shown in Figure 2, and the specimens are summarized in Table 2. The specimen details are shown in Figure 3. The prestressing force was introduced as $94 \%$ of the yield strength of the strand when the compressive strength of concrete was $32 \mathrm{MPa}$.

3.2. Test Setup. As shown in Figure 4, the specimens were simply supported and subjected to four-point loading. The distance from support to loading point was $1500 \mathrm{~mm}$, and the distance between the two central point loads was $600 \mathrm{~mm}$. A hydraulic universal testing machine (UTM) was used to apply a load of $5000 \mathrm{kN}$ at a rate of $2 \mathrm{~mm} / \mathrm{min}$. Strain

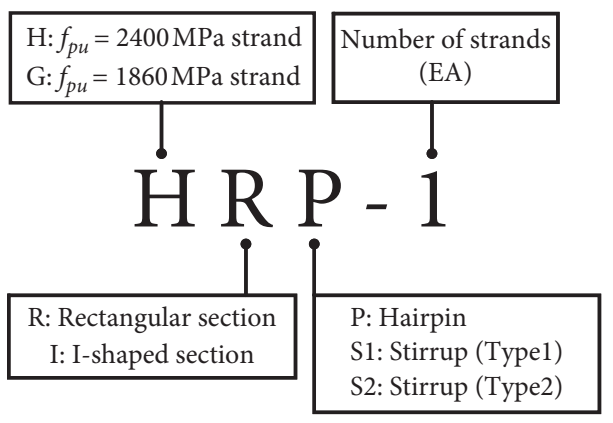

Figure 2: Notation used for specimens.

gauges were attached as shown in Figure 5, and deflection was measured at midspan with three LVDTs on the bottom of the specimens.

\section{Experimental Results and Analysis}

4.1. Failure Mode and Crack Pattern. The crack patterns and failure of the specimens are shown in Figures 6 and 7. Specimens showed flexural cracking in the pure moment region during the initial loading stage. As applied load was increased, the flexural crack width extended and numerous flexural cracks grew vertically in the maximum moment region. As the tensile strength of strands increased, the number of flexural cracks decreased, and the cracks of specimens using Grade 1860 strands progressed toward the compression zone more than specimens using Grade 2400 strands. This is because the depth of neutral axis of members with Grade 2400 strands increased more than that of members with Grade 1860 strands. Spacing of main cracks of the specimen using Grade 2400 strands was approximately $200 \mathrm{~mm}$, and the specimen with Grade 1860 strands was $181 \mathrm{~mm}$ in the test specimens with rectangular cross section. In the specimens with I-shaped cross section, the specimen with Grade 2400 strands was about $140 \mathrm{~mm}$ and the specimen with Grade 1860 strand was $90 \mathrm{~mm}$. Wider crack spacing was observed in the specimens using Grade 2400 strands. Many researchers have found that plastic hinge length is a critical parameter for determination of ultimate stress increase in strands $[7,8,11,12]$. Plastic hinge length is proportional to ultimate deflection [13]. Therefore, short plastic hinge length reduces beam deflection. It was observed that the plastic hinge lengths of HRP-1 and HIP-1 using Grade $2400 \mathrm{MPa}$ were reduced than those of GRP-1 and GIP-1 using conventional Grade $1860 \mathrm{MPa}$ as shown in Figure 6. In the rectangular 
TABLE 2: Details of experiment specimens.

\begin{tabular}{|c|c|c|c|c|c|c|c|c|c|}
\hline No. & Specimen & $f_{c}^{\prime}(\mathrm{MPa})$ & $f_{y}(\mathrm{MPa})$ & $f_{p u}(\mathrm{MPa})$ & Section & EA & $\rho_{p}$ & $\mathrm{e}(\mathrm{mm})$ & Anchorage zone reinforcement \\
\hline 1 & HRP-1 & & & 2400 & Rectangular & 1 & 0.000627 & & \\
\hline 2 & HIP-1 & & & 2400 & I-shape & 1 & 0.000822 & & \\
\hline 3 & GRP-1 & & & 1860 & Rectangular & 1 & 0.000627 & & Hairpin \\
\hline 4 & GIP-1 & & & 1860 & I-shape & 1 & 0.000822 & & \\
\hline 5 & HRP-2 & & & & & 2 & 0.001254 & & \\
\hline 6 & HRP-3 & 35 & 400 & & & 3 & 0.001881 & 120 & Hairpin \\
\hline 7 & HRS1-3 & & & & & 3 & 0.001881 & & Stirrup (Type 1) \\
\hline 8 & HRS2-3 & & & 2400 & Rectangular & 3 & 0.001881 & & Stirrup (Type 2) \\
\hline 9 & HRP-4 & & & & & 4 & 0.002508 & & Hairpin \\
\hline 10 & HRS1-4 & & & & & 4 & 0.002508 & & Stirrup (Type 1) \\
\hline 11 & HRS2-4 & & & & & 4 & 0.002508 & & Stirrup (Type 2) \\
\hline
\end{tabular}

$f_{c}^{\prime}$ : compressive strength of concrete, $f_{y}$ : yield strength of reinforcement, $f_{p u}$ : tensile strength of prestressing steel, e: eccentricity of prestressing steel, and $\rho_{p}$ : ratio of $A_{p s}$ to $\mathrm{b} d_{p}$.

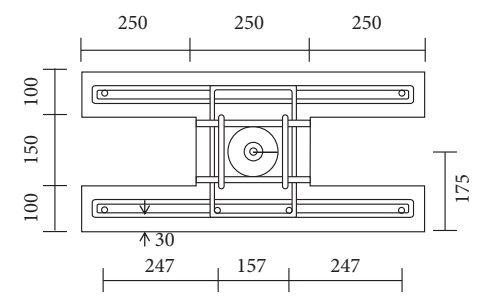

(a)

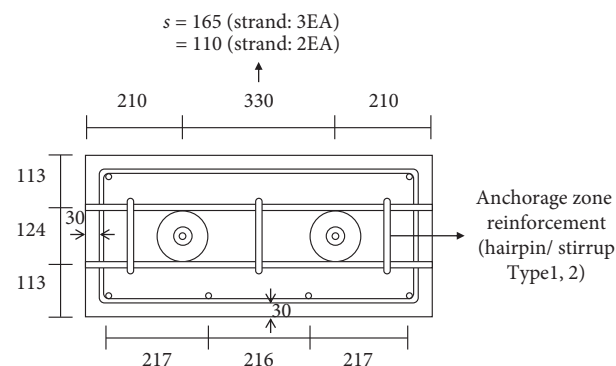

(c)

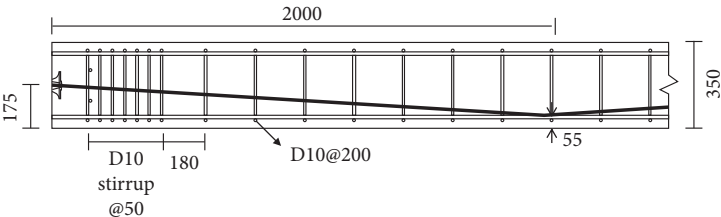

(e)

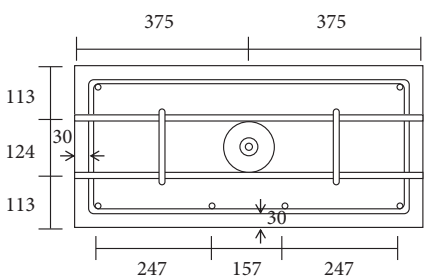

(b)

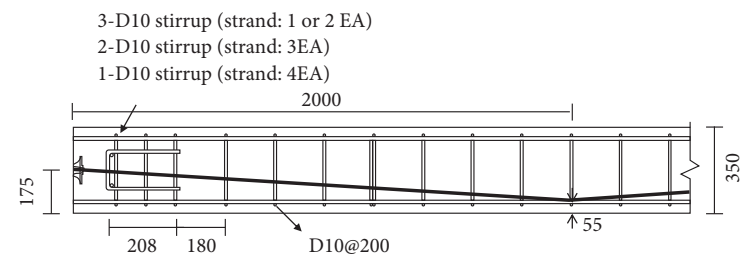

(d)

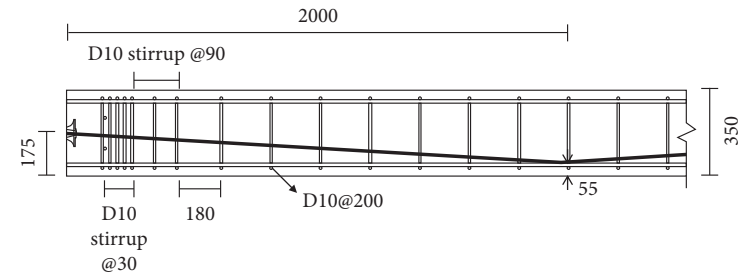

(f)

FIgURE 3: Details of specimens (mm). (a) Front view of HIP-1 and GIP-1; (b) front view of HRP-1 and GRP-1; (c) front view of the other specimens; (d) side view of reinforced hairpin specimens; (e) side view of reinforced stirrup specimens (Type 1); and (f) side view of reinforced stirrup specimens (Type 2).

specimens, more flexural cracks occurred in the rectangular specimens around the bottom flanges than in the I-shaped specimen, as shown in Figures 6(a)-6(d). The crack spacing of I-shaped specimens decreased more than that of rectangular specimens with the same tensile strength strands. In the case of the specimens using Grade 1860 strands, crushing on the compression zone of concrete was observed in the HIP-1 specimen. These results show that the I-shaped specimen, which had a smaller cross section than the rectangular specimen, acted as an overreinforced section because the reinforcement ratio and number of strands in were the same in both specimens. The prestressed concrete member needs to be designed based on tensile stresses and cracking $[5,14]$. In this study, the crack pattern was analyzed according to the amount of prestressing steel. In the specimens with Grade 2400 strands, crack propagation decreased as the number of strands increased, and the average crack spacing decreased from $257 \mathrm{~mm}$ to $180 \mathrm{~mm}, 179.3 \mathrm{~mm}$, and $157.1 \mathrm{~mm}$ as the number of strands increased from 1 to 4 . As shown in Figures $6(\mathrm{f})-6(\mathrm{~h})$ and Figures $6(\mathrm{i})-6(\mathrm{k})$, the cracking pattern 


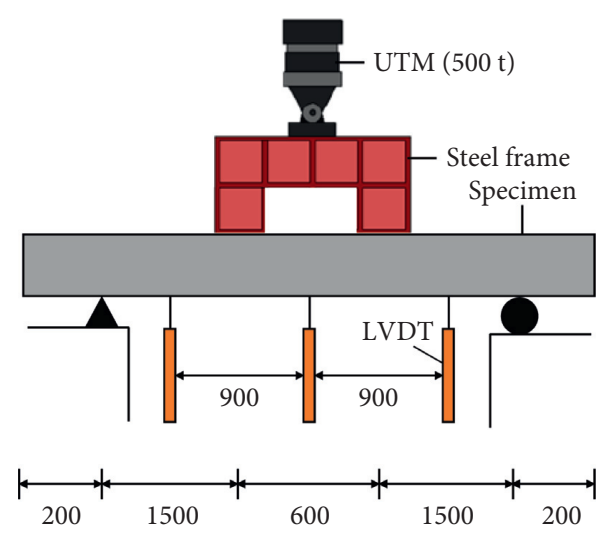

(a)

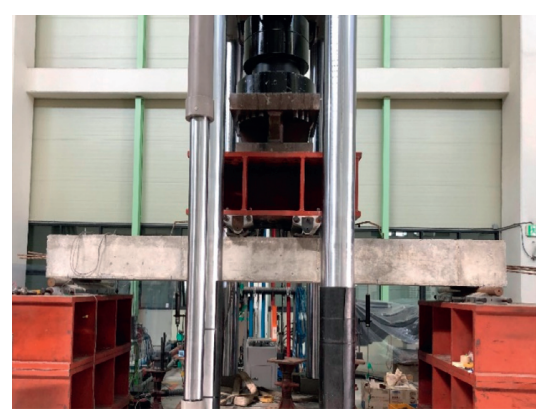

(b)

Figure 4: Test setup. (a) Schematic test setup. (b) Photograph of test setup.

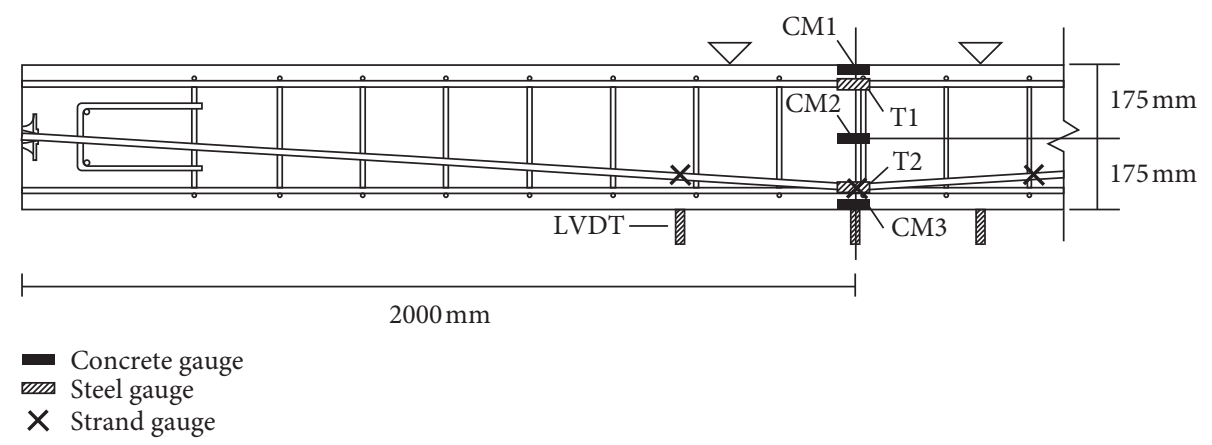

FIgURE 5: Positions and naming of gauges.

was similar regardless of the anchorage zone reinforcement detail and concrete fracture was observed in the anchorage zone of the HRS1-3 specimen, which had D10 stirrups with $50 \mathrm{~mm}$ spacing, as shown in Figure 7(e). This is because the anchorage zone reinforcement is designed to resist the bursting force and bearing force applied in the anchorage zone, but it could not resist the increased compressive force at the anchorage due to the increasing load on the specimen. The damage level of the specimens at each step of the loading is presented in Figure 8 to compare the influence of different parameters. The damage states proposed by Pagni and Lowes [15] were modified to be suitable for this study as follows:

(1) Not cracking

(2) Initial hairline cracking at the slab

(3) Maximum crack width is less than $0.5 \mathrm{~mm}$

(4) Maximum crack width is greater than $0.5 \mathrm{~mm}$

(5) Longitudinal reinforcement yield

(6) Maximum crack width is greater than $1.3 \mathrm{~mm}$

(7) Maximum crack width is greater than $2 \mathrm{~mm}$

(8) Spalling of at least $10 \%$ of the middle of slab

(9) Failure

High-strength strands were more effective in crack control than conventional strands. The number of strands and anchorage zone reinforcement details had little effect on the degree of damage of the posttensioned concrete member.

4.2. Load-Displacement and Load-Strain Relationships. Figure 9 plots the load-displacement response for each specimen. The maximum moment $\left(M_{u}\right)$ obtained from the experimental results compared to the nominal moment and design moment predicted from ACI 318 code is presented in Table 3. The design moment is calculated by multiplying the strength reduction factor $\varnothing$ by the nominal moment. The specimens applying Grade 1860 strands and Grade 2400 strands, as shown in Figure 9(a), exhibited a linear response with equal stiffness before cracking. The ultimate strengths of specimens GRP-1 and GIP-1 were $177.7 \mathrm{kN}$ and $174.4 \mathrm{kN}$, respectively, so there was no difference in flexural performance according to the cross-sectional shape. This is because the neutral axis of the I-shaped specimen was located at the upper flange so that it had the same flexural behavior as the rectangular specimen. Although the tensile strength of the Grade $2400 \mathrm{MPa}$ was $29 \%$ higher than that of the $1860 \mathrm{MPa}$ strands, the HRP-1 and HIP-1 with the tensile strength of the strand $2400 \mathrm{MPa}$ showed a flexural strength $14.5 \%$ greater than that of GRP-1 and GIP-1. Relative to the specimen with one strand, the flexural strength of specimens with two, three, and four strands were $42.5 \%, 51.4 \%$, and $13.8 \%$ higher, respectively. Therefore, it would have effective influence of 


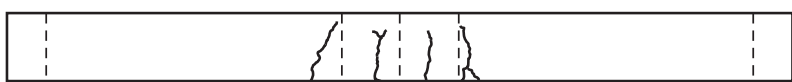

(a)

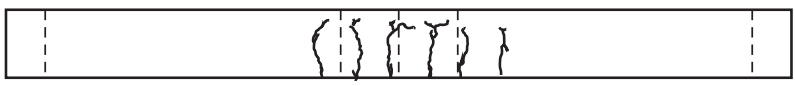

(c)

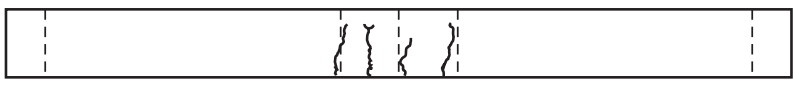

(e)

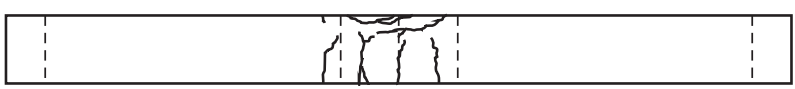

(g)

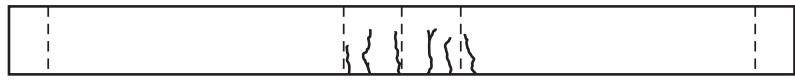

(i)

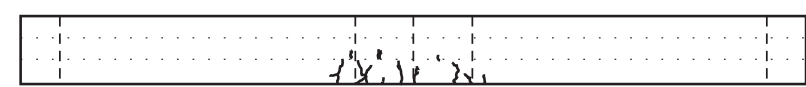

(b)

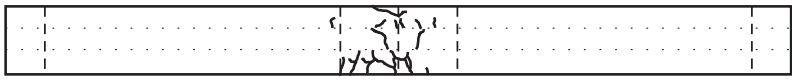

(d)



(f)



(h)

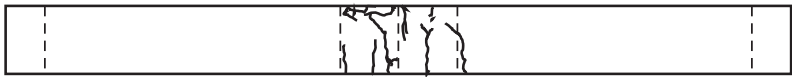

(j)

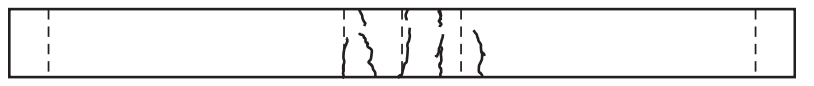

(k)

FiguRE 6: Crack patterns of specimens. (a) HRP-1; (b) HIP-1; (c) GRP-1; (d) GIP-1; (e) HRP-2; (f) HRP-3; (g) HRS1-3; (h) HRS2-3; (i) HRP4; (j) HRS1-4; and (k) HRS2-4.

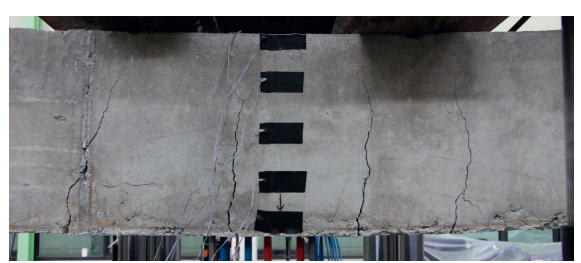

(a)

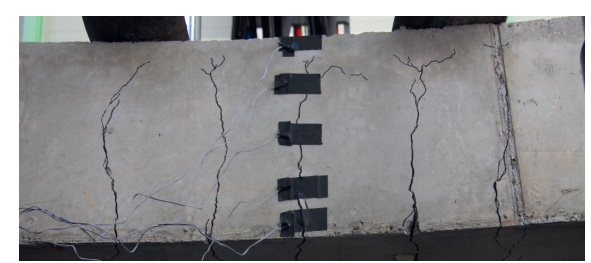

(b)

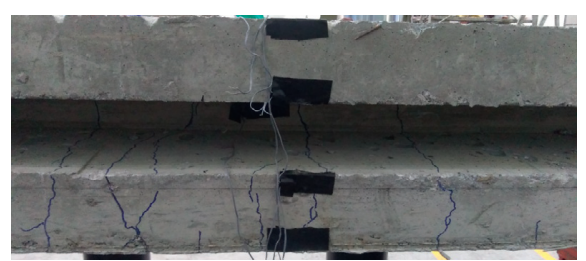

(c)

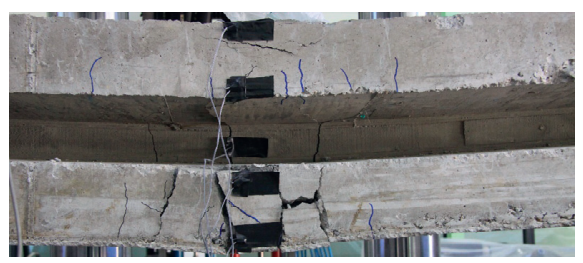

(d)

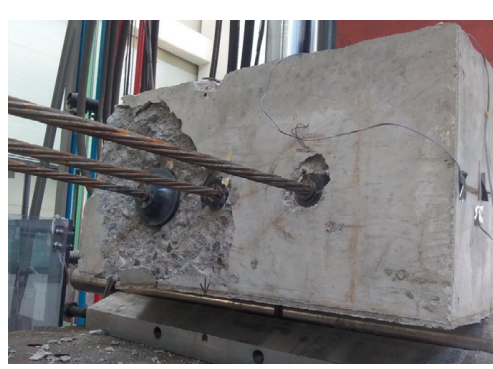

(e)

Figure 7: Failure after experiment. (a) HRP-1; (b) GRP-1; (c) HIP-1; (d) GIP-1; and (e) HRS1-3.

flexural performance for applying Grade 2400 strands rather than Grade 1860 strands. As shown in Table 3, the ACI 31819 code underestimated the moment of posttensioned members with unbonded strands. In particular, the ratio between maximum moment and design moment of the specimens using Grade 2400 strands was 1.34 on average, so this approach does not work well for high-strength strands. It was concluded that the stress of strands $\left(f_{p s}\right)$, which is considered when calculating flexural strength in ACI 318-19, is not considered in Grade 2400 strands.

The load-strain relationship of concrete and bonded tensile reinforcement was analyzed according to the tensile strength of the strands. As shown in Figure 10, the concrete strain changed similarly until the cracking regardless of the tensile strength of strands in the compression zone. Over $100 \mathrm{kN}$, cracking occurs. The concrete strain of GRP-1, which used Grade 1860 strands, increased more than that of HRP-1, which used Grade 2400 strands, because the introduced prestressing force is low so that large deformation occurred at the same loading stage. On the bottom of the member, the concrete strain of the GRP-1 specimen was almost zero before cracking and increased sharply so that it exceeded 0.003 , the yield strain of concrete, and plastic deformation occurred. The load-strain relationship of 


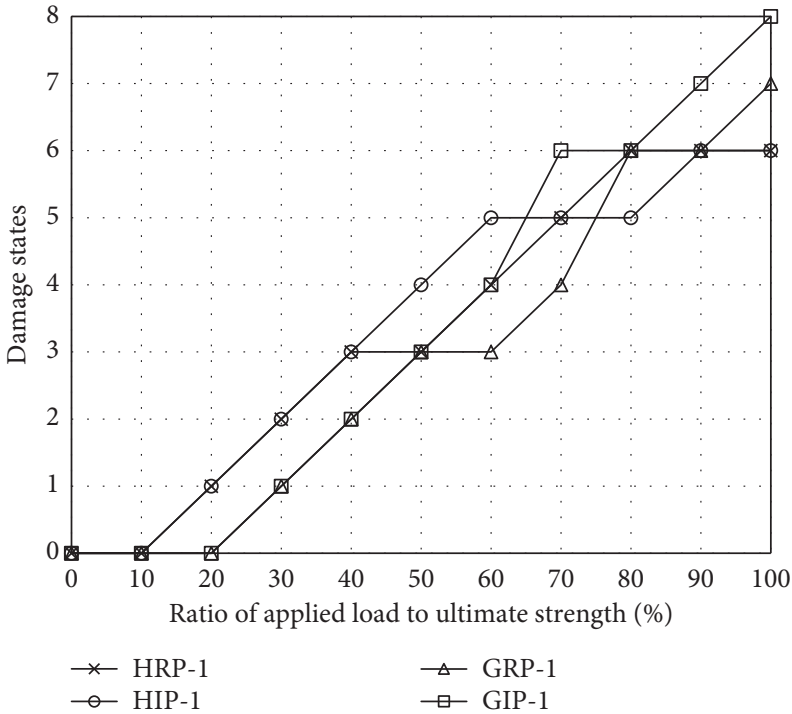

(a)

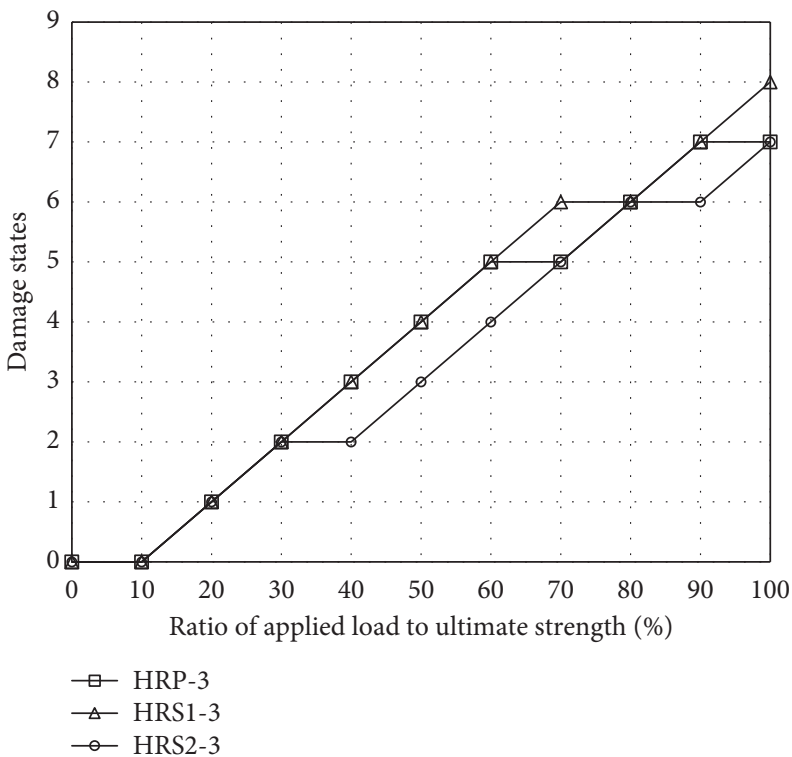

(c)

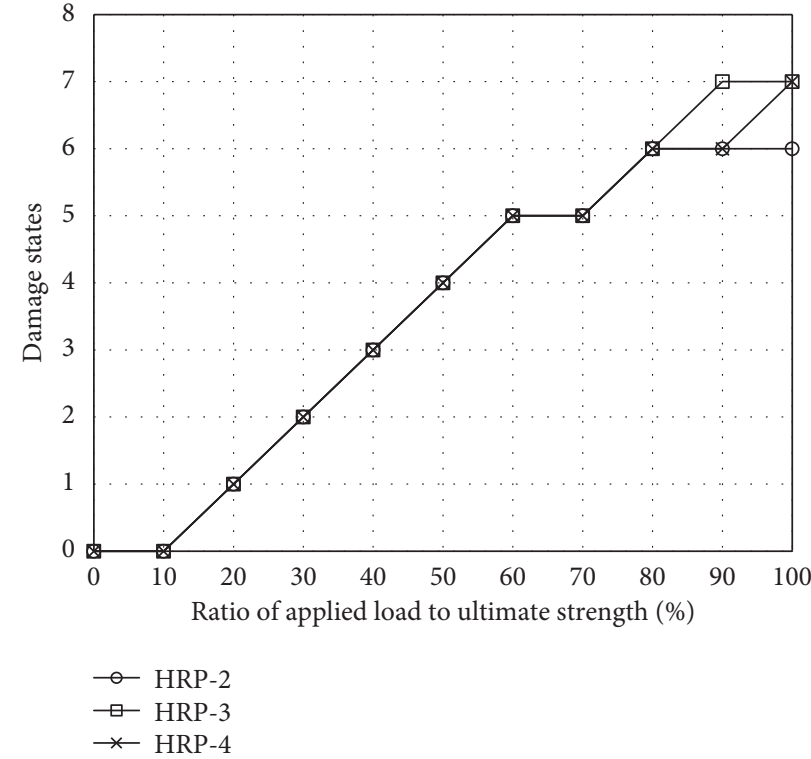

(b)



(d)

Figure 8: Damage states according to applied load. (a) Specimens with tensile strength of strands as a variable; (b) specimens with number of strands as a variable; (c) specimens using three strands for varying anchorage zone reinforcement types; (d) specimens using four strands for varying anchorage zone reinforcement types.

reinforcing steel bars is shown in Figure 11. Regardless of the tensile strength of the strands, there was no deformation in compressive reinforcement. The bonded reinforcements placed on the bottom fiber of the member exceeded the yield strain at $140 \mathrm{kN}$ and $134.05 \mathrm{kN}$ for the HRP-1 and GRP-1 specimens, respectively, and the deformation increased sharply.

\subsection{Evaluation of the Equation for Stress in Unbonded Strands.} To analyze the applicability of unbonded high-strength strands in current design codes and equations for stress in unbonded strands, the increase of stress in the prestressed strand $\left(\Delta f_{p s}\right)$ estimated by experiment and predicted by current codes $[3,4]$ and equations of Du and Tao, Naaman and Alkhari, and Harajli [6-8] was compared as shown in Figure 12 and Table 4. Table 5 lists the average, standard deviation, and covariance of each equation. All equations underestimated $\Delta f_{p s}$. It is inferred that the equations provided conservative predictions because they limited the stress in the unbonded strands from exceeding the $f_{p y}$. In addition, $\Delta f_{p s}$ decreased more sharply with increasing numbers of strands than experimental results. The ACI 31819 standard [3] underestimated $\Delta f_{p s}$ by 2.6 times to 


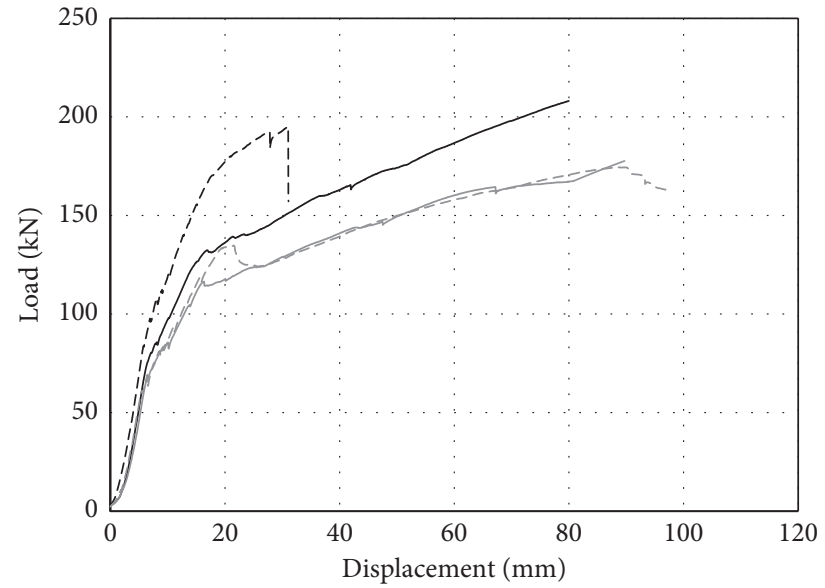

- HRP-1
GRP-1

GIP-1
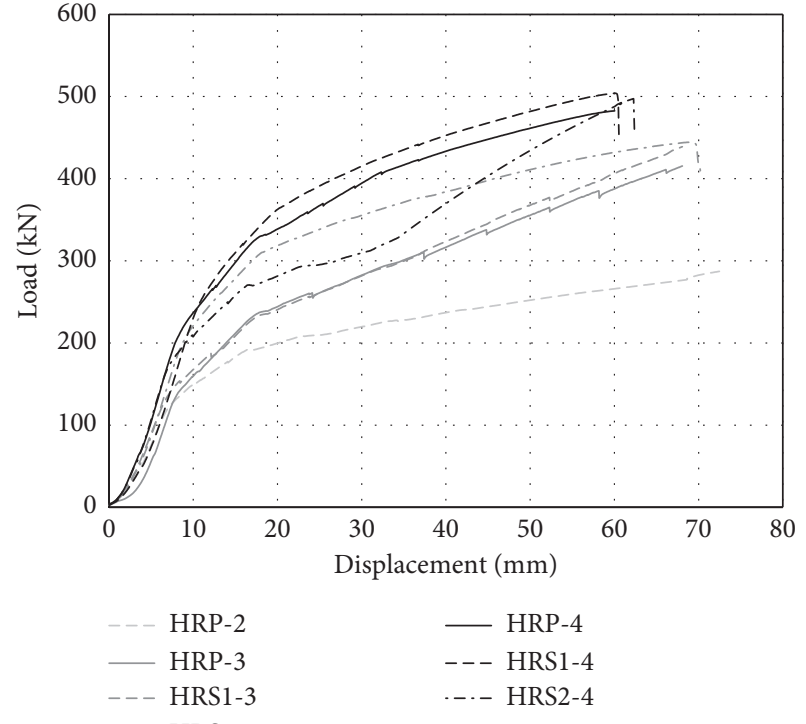

(b)

Figure 9: Load-displacement relationship. Comparison of load-displacement relationship for (a) varying cross sections and tensile strengths and (b) varying numbers of strands and anchorage zone reinforcement types.

Table 3: Test results.

\begin{tabular}{|c|c|c|c|c|c|c|}
\hline \multirow{2}{*}{ No. } & \multirow{2}{*}{ Specimen } & \multicolumn{3}{|c|}{ Ultimate state } & \multirow{2}{*}{$\left(M_{u}\right.$, test $) /\left(M_{n}, \mathrm{ACI}\right)$} & \multirow{2}{*}{$\left(M_{u}\right.$, test $) /\left(M_{d}, \mathrm{ACI}\right)$} \\
\hline & & $P_{u}(\mathrm{kN})$ & $M_{u}(\mathrm{kN}-\mathrm{m})$ & $\Delta_{u}(\mathrm{~mm})$ & & \\
\hline 1 & HRP-1 & 208.092 & 156.069 & 79.931 & 1.174 & 1.304 \\
\hline 2 & HIP-1 & 195.161 & 146.371 & 31.033 & 1.101 & 1.223 \\
\hline 3 & GRP-1 & 177.703 & 133.277 & 89.701 & 1.102 & 1.224 \\
\hline 4 & GIP-1 & 174.442 & 130.832 & 89.700 & 1.081 & 1.202 \\
\hline 5 & HRP-2 & 287.214 & 215.411 & 72.466 & 1.089 & 1.210 \\
\hline 6 & HRP-3 & 420.837 & 315.628 & 68.269 & 1.249 & 1.387 \\
\hline 7 & HRS1-3 & 438.948 & 329.211 & 68.066 & 1.302 & 1.447 \\
\hline 8 & HRS2-3 & 443.963 & 332.972 & 68.265 & 1.317 & 1.463 \\
\hline 9 & HRP-4 & 482.629 & 361.972 & 60.034 & 1.184 & 1.316 \\
\hline 10 & HRS1-4 & 504.051 & 378.038 & 60.071 & 1.237 & 1.374 \\
\hline 11 & HRS2-4 & 407.309 & 372.982 & 62.278 & 1.220 & 1.356 \\
\hline
\end{tabular}

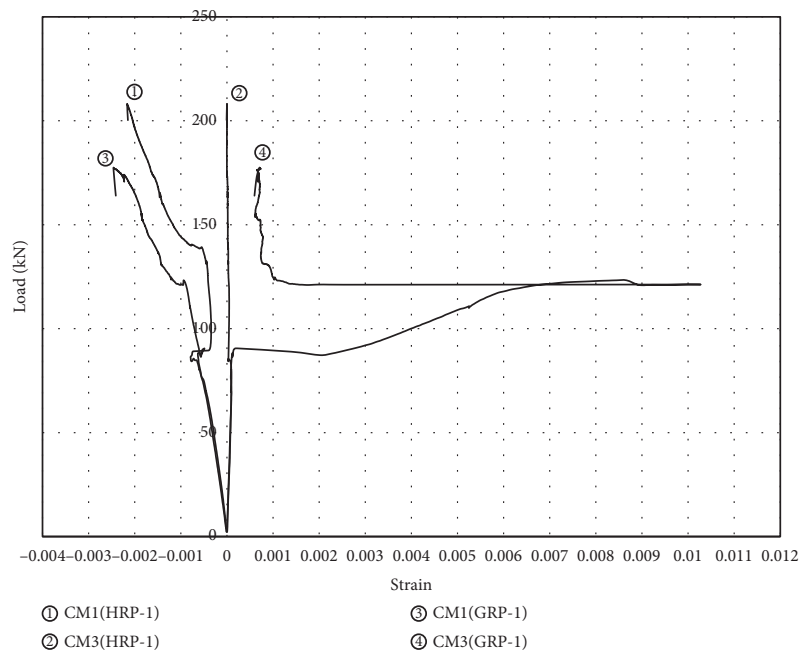

Figure 10: Concrete strain.

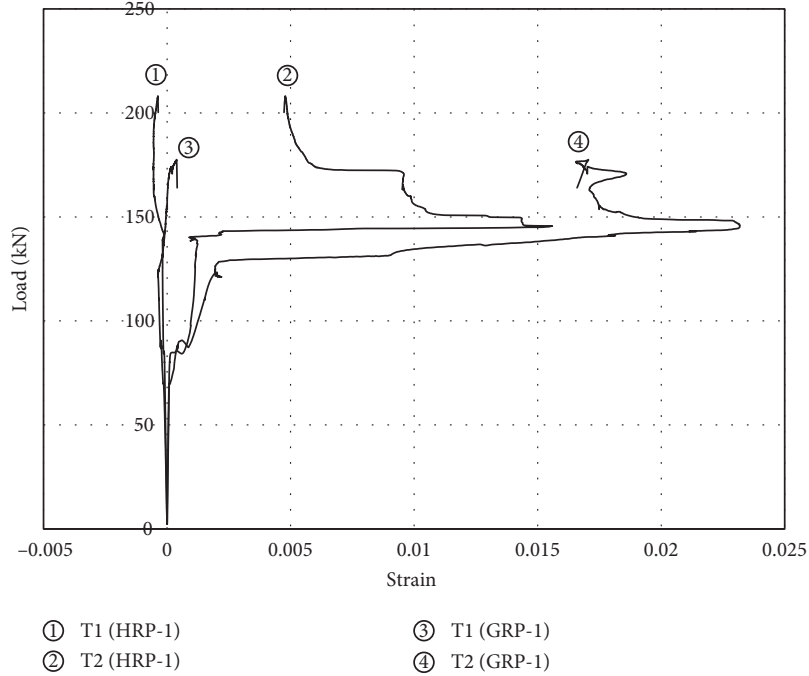

Figure 11: Rebar strain. 


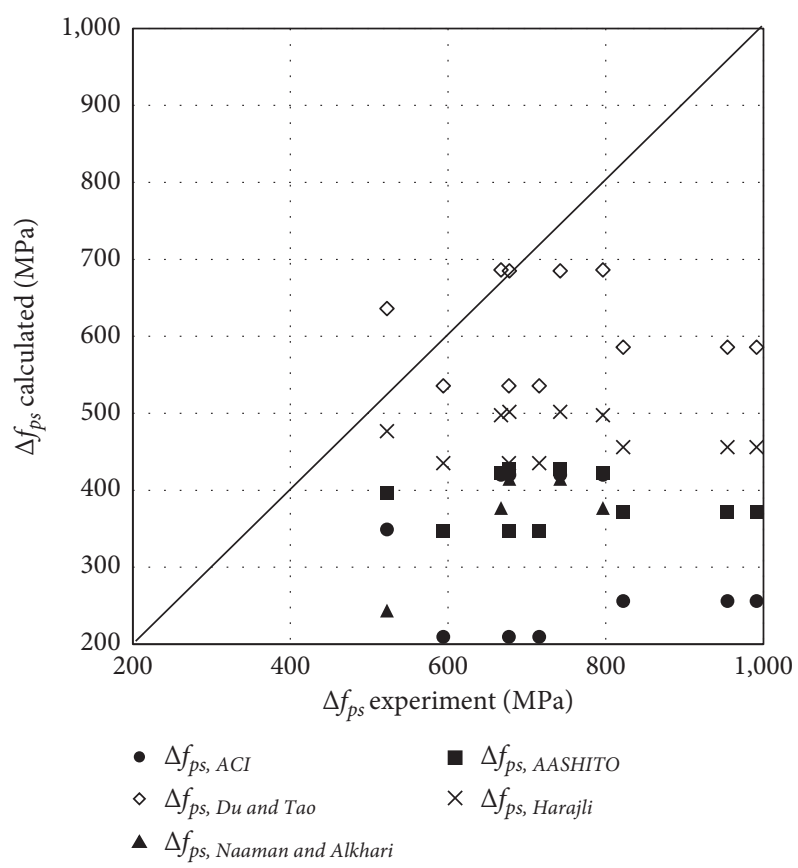

FIgURE 12: Comparison of predictions of increase of stress in strands.

TABLE 4: Comparison of stress increase in unbonded tendons at ultimate.

\begin{tabular}{|c|c|c|c|c|c|c|c|}
\hline No. & Specimen & $\Delta f_{\mathrm{ps}, \mathrm{test}}(\mathrm{MPa})$ & $\Delta f_{\mathrm{ps}, \mathrm{ACI}}(\mathrm{MPa})$ & $\Delta f_{\mathrm{ps}, \mathrm{Du} \text { and Tao }}(\mathrm{MPa})$ & $\Delta f_{\mathrm{ps}, \text { Naaman and Alkhari }}(\mathrm{MPa})$ & $\Delta f_{\mathrm{ps}, \mathrm{AASHTO}}(\mathrm{MPa})$ & $\begin{array}{c}\Delta f_{\mathrm{ps}, \text { Harajli }} \\
\quad(\mathrm{MPa})\end{array}$ \\
\hline 1 & HRP-1 & 796.362 & 420 & 686.311 & 377.002 & 421.825 & 497.518 \\
\hline 2 & HIP-1 & 667.063 & 420 & 686.311 & 377.002 & 421.825 & 497.518 \\
\hline 3 & GRP-1 & 742.022 & 420 & 684.848 & 414.772 & 427.204 & 501.976 \\
\hline 4 & GIP-1 & 677.773 & 420 & 684.848 & 414.772 & 427.204 & 501.976 \\
\hline 5 & HRP-2 & 522.528 & 349.155 & 636.047 & 243.788 & 396.891 & 476.795 \\
\hline 6 & HRP-3 & 821.911 & 256.103 & 585.783 & 177.724 & 371.956 & 456.071 \\
\hline 7 & HRS1-3 & 954.283 & 256.103 & 585.783 & 177.724 & 371.956 & 456.071 \\
\hline 8 & HRS2-3 & 991.060 & 256.103 & 585.783 & 177.724 & 371.956 & 456.071 \\
\hline 9 & HRP-4 & 593.847 & 209.577 & 535.519 & 137.539 & 347.021 & 435.348 \\
\hline 10 & HRS1-4 & 715.608 & 209.577 & 535.519 & 137.539 & 347.021 & 435.348 \\
\hline 11 & HRS2-4 & 677.122 & 209.577 & 535.519 & 137.539 & 347.021 & 435.348 \\
\hline
\end{tabular}

TABle 5: Statistical data obtained from the comparison between experimental tendon stresses by the test results and existing equations.

\begin{tabular}{lccccc}
\hline Equation & ACI & $\begin{array}{c}\text { Du and } \\
\text { Tao }\end{array}$ & $\begin{array}{c}\text { Naaman and } \\
\text { Alkhari }\end{array}$ & AASHTO & Harajli \\
\hline Mean & 2.604 & 1.224 & 3.587 & 1.934 & 1.591 \\
SD & 0.893 & 0.261 & 1.588 & 0.398 & 0.312 \\
COV & 0.343 & 0.213 & 0.443 & 0.206 & 0.196 \\
\hline
\end{tabular}

experimental results. It was because of drawbacks of the ACI building code that neglected the effect of bonded tension reinforcement to the increase in stress of strands in specimens HRP-1, HIP-1, GRP-1, and GIP-1, which have a ratio of strands smaller than 0.001 , the stress of strands $\left(f_{p s}\right)$ exceeded $f_{p e}+420 \mathrm{MPa}$ so that it is predicted to have a smaller value than the real $\Delta f_{s}$. In ACI 318-19, the coefficient that is multiplied by $\rho_{p}$ in $\Delta f_{s}$ is kept at 100 regardless of the prestressing steel ratio $\left(\rho_{p}\right)$, but according to the experimental results, when the prestressing steel ratio is larger than 0.002, the coefficient should be about 25. From these observations, in the case of highstrength strands, the coefficient of the strand ratio should be modified. Although both the AASHTO code [4] and the ACI design code conservatively estimated the $\Delta f_{p s}$ of all specimens, the AASHTO design code provides better predictions than the ACI 318 design code about the increase in stress in prestressed strands according to the variations in the prestressing steel ratio. It is inferred that this is because the AASHTO code considers the effect of the prestressing steel ratio to flexural behavior, because $\Delta f_{s}$ is calculated by the ratio of the effective depth of strands excepting the depth of the neutral axis and the effective length of strands. However, the accuracy of the predicting equation is still low and the predicted values of $\Delta f_{s}$ are scattered, so the values of $\Delta f_{s}$ calculated by AASHTO code are not reliable. The average value of the test result divided by $\Delta f_{s}$ calculated using $\mathrm{Du}$ and Tao's equation [6] was 1.224, which is quite accurate 
compared to current codes. The influence of the prestressing steel ratio and bonded reinforcements was raised as the main reasons for the large difference between current codes and experimental results; it is because the reinforcing index of strands and the reinforcing index of the bonded reinforcement are introduced to consider the influence of the amount of bonded reinforcement to stress in the strands. However, in the cases when the tensile strength of strands was $1860 \mathrm{MPa}$ and $2400 \mathrm{MPa}$, the ratios between the experimental result and the value calculated by the $\mathrm{Du}$ and Tao equation were 1.037 and 1.265, respectively. Although Naaman and Alkhari's equation [7] considered significant factors that affect the stress in the strand, $\Delta f_{s}$ has a mean of 3.587 and a standard deviation of 1.588. In addition, the average of the decrease in $\Delta f_{s}$ with increasing prestressing steel was 2.14 , while the experimental results observed 1.1. It is inferred that the bond-reduction coefficient, which is derived to consider unbonded behavior of unbonded strands, was not reasonable for high-strength strands, because high-strength strands showed behavior more similar to bonded strands than the conventional strands, for a given number of strands. From this observation, the consideration for the effect in bond reduction of high-strength unbonded strands should be derived. Harajli's equation [8] provided a reasonable prediction of the decreasing tendency of $\Delta f_{s}$ with increasing numbers of strands, but most results underestimated the experimental values. The difference between experimental results and calculated values tended to increase. This observation can be attributed to the fact that the number of plastic hinges and loading patterns, which were considered in Haraili's equation [8], were not affected by the amount of prestressing steel, while the ratio of plastic hinge length and maximum moment region decreased with increasing numbers of strands. It is concluded that the number of high-strength strands should be considered in plastic hinge length calculation.

\section{Conclusions}

In order to examine the applicability of high-strength strands to current design codes and the proposed equations, a flexural experiment was undertaken on eleven specimens with varying strand tensile strength, number of strands, cross-section shape, and reinforcement details in the anchorage zone. The following conclusions were drawn from this study:

(1) The flexural cracks of specimens with high-strength strands expanded deeper into the compression zone compared to the specimens with Grade 1860 strands. As the prestressing steel ratio increases, the number of flexural cracks increased and the crack spacing decreased. The spacing between cracks of the I-shaped specimens decreased compared to the rectangular specimens regardless of the strand tensile strength, and crushing of concrete was observed in the compression zone. The cracking patterns were similar regardless of anchorage zone reinforcement details. In the specimen whose anchorage zone was reinforced by stirrups, the concrete in the anchorage zone could not resist the increased compressive stress due to the increased bending moment.

(2) The flexural strength of specimens using Grade 2400 strands increased $14.5 \%$ more than that of specimens using Grade 1860 strands. There was insignificant variation in ultimate strength depending on the cross-section shape. The design flexural strengths calculated based on ACI 318-19 were shown to be conservative compared to the experimental results.

(3) The provisions of ACI and AASHTO codes and proposed equations underestimated the increase of stress in the strand. In addition, $\Delta f_{p s}$ decreased more sharply with an increasing amount of strands than experimental results. This can be explained by the increased bond strength and reduced plastic hinge length when using high-strength strands.

(4) The analysis results indicate that existing equations need to be revised to account for the increase in the bond strength and reduced plastic hinge length of high-strength strands. To achieve more accurate stress prediction for high strands, more experimental and analytical studies are needed.

\section{Data Availability}

The data used to support the findings of this study are available from the corresponding author upon request.

\section{Conflicts of Interest}

The authors declare that there are no conflicts of interest regarding the publication of this paper.

\section{Acknowledgments}

This work was supported by the National Research Foundation of Korea (NRF) funded by the Korean government (MSIT) (NRF-2017R1A2B2005581).

\section{References}

[1] H. Park, S. Jeong, S.-C. Lee, and J.-Y. Cho, "Flexural behavior of post-tensioned prestressed concrete girders with highstrength strands," Engineering Structures, vol. 112, pp. 90-99, 2016.

[2] J. H. Park, H. Park, and J. Y. Cho, "Prediction of stress in bonded strands at flexural strength," ACI Structural Journal, vol. 114, no. 3, pp. 697-705, 2017.

[3] ACI Committee 318, Building Code Requirements for Reinforced Concrete and Commentary (ACI 318-19), American Concrete Institute, Farmington Hills, MI, USA, 2019.

[4] American Association of State and Highway Transportation Officials, AASHTO LRFD Bridge Design Specifications, American Association of State and Highway Transportation Officials, Washington, DC, USA, 2010.

[5] C. G. Karayannis and C. E. Chalioris, "Design of partially prestressed concrete beams based on the cracking control provisions," Engineering Structures, vol. 48, pp. 402-416, 2013. 
[6] G. Du and X. Tao, "Ultimate stress of unbonded tendons in partially prestressed concrete beams," PCI Journal, vol. 30, no. 6, pp. 72-97, 1985.

[7] A. E. Naaman and F. M. Alkhairi, "Stress at ultimate in unbonded post-tensioning tendons: part 2. Proposed methodology," ACI Structural Journal, vol. 88, no. 6, pp. 683-692, 1992.

[8] M. H. Harajli, "Proposed modification of AASHTO-LRFD for computing stress in unbonded tendons at ultimate," Journal of Bridge Engineering, vol. 16, no. 6, pp. 828-838, 2010.

[9] A. H. Mattock, J. Yamazaki, and B. T. Kattula, "Comparative study of prestressed concrete beams, with and without bond," Journal Proceedings, vol. 68, no. 2, pp. 116-125, 1971.

[10] S. Mojtahedi and W. L. Gamble, "Ultimate steel stresses in unbonded prestressed concrete," Journal of the Structural Division, vol. 104, no. 7, pp. 1159-1164, 1978.

[11] C. L. Roberts-Wollmann, M. E. Kreger, D. M. Rogowsky, and J. E. Breen, "Stresses in external tendons at ultimate," $A C I$ Structural Journal, vol. 102, no. 2, pp. 206-213, 2005.

[12] R. J. G. MacGregor, Strength and Ductility of Externally Posttensioned Segmental Box Girders," PhD Dissertation, The University of Texas at Austin, Austin, TX, USA, 1989.

[13] Z.-Q. He and Z. Liu, "Stresses in external and internal unbonded tendons: unified methodology and design equations," Journal of Structural Engineering, vol. 136, no. 9, pp. 1055-1065, 2010.

[14] C. G. Karayannis and C. E. Chalioris, "Strength of prestressed concrete beams in torsion," Structural Engineering and Mechanics, vol. 10, no. 2, pp. 165-180, 2000.

[15] C. A. Pagni and L. N. Lowes, "Fragility functions for older reinforced concrete beam-column joints," Earthquake Spectra, vol. 22, no. 1, pp. 215-238, 2006. 